\title{
Expression of monoamine transporters, nitric oxide synthase 3, and neurotrophin genes in antidepressant-stimulated astrocytes
}

\author{
Sarah Kittel-Schneider ${ }^{1}$, Gunter Kenis ${ }^{2}$, Julia Schek ${ }^{1}$, Daniel van den Hove ${ }^{1,2}$, Jos Prickaerts ${ }^{2}$, \\ Klaus-Peter Lesch ${ }^{1,2}$, Harry Steinbusch ${ }^{2}$ and Andreas Reif ${ }^{1}$ * \\ Department of Psychiatry, Psychosomatics and Psychotherapy, Psychiatric Neurobiology and Bipolar Disorder Program, University of Würzburg, Würzburg, \\ Germany \\ ${ }^{2}$ Department of Psychiatry and Neuropsychology, School for Mental Health and Neuroscience, Maastricht University, Maastricht, Netherlands
}

\section{Edited by:}

Sulie L. Chang, Seton Hall University, USA

\section{Reviewed by:}

Ju Wang, University of Virginia, USA Konrad Prasad, University of

Pittsburgh School of Medicine, USA

Shuxian Hu, University of Minnesota, USA

\section{*Correspondence:}

Andreas Reif, Department of

Psychiatry, Psychosomatics and

Psychotherapy, Psychiatric

Neurobiology and Bipolar Disorder

Program, University of Würzburg,

Füchsleinstr. 15, D-97080 Würzburg,

Germany.

e-mail: reif_a@klinik.uni-wuerzburg.de
Background:There is increasing evidence that glial cells play a role in the pathomechanisms of mood disorders and the mode of action of antidepressant drugs. Methods: To examine whether there is a direct effect on the expression of different genes encoding proteins that have been implicated in the pathophysiology of affective disorders, primary astrocyte cell cultures from rats were treated with two different antidepressant drugs, imipramine and escitalopram, and the RNA expression of brain-derived neurotrophic factor (Bdnf), serotonin transporter $(5 \mathrm{Htt})$, dopamine transporter $(D a t)$, and endothelial nitric oxide synthase (Nos3) was examined. Results: Stimulation of astroglial cell culture with imipramine, a tricyclic antidepressant, led to a significant increase of the Bdnf RNA level whereas treatment with escitalopram did not. In contrast, $5 \mathrm{Htt}$ was not differentially expressed after antidepressant treatment. Finally, neither Dat nor Nos3 RNA expression was detected in cultured astrocytes. Conclusion: These data provide further evidence for a role of astroglial cells in the molecular mechanisms of action of antidepressants.

Keywords: antidepressant, mechanism of action, BDNF, nitric oxide synthase, gene expression, depression, glia, astrocytes

\section{INTRODUCTION}

Major depressive disorder (MDD) is one of the most prevalent psychiatric disorders. Its debilitating long-term course causes severe psychosocial consequences in the affected individuals and a high economic burden. More patients than previously thought do not completely recover and display permanent depressive symptoms and even persisting cognitive deficits (Manji et al., 2000; Pittenger and Duman, 2008). Worldwide up to $15 \%$ of a given population, women more often than men, experience a major depressive episode at least once in a lifetime (Bromet et al., 2011) and 50\% of the patients who had one depressive episode will suffer from recurrent depressive episodes (Kupfer, 1991). About 11\% of individuals suffering from a mood disorder were found to commit suicide (Angst et al., 2005). The heritability of MDD was estimated at about 37\% (Sullivan et al., 2000), adding evidence to its complex etiology. While not only the molecular mechanisms of MDD are still elusive, also the downstream mechanisms of the mode of action of antidepressants remain uncertain; while the primary targets are well known, subsequent molecular processes underlying the delayed clinical effects are not. Recent research pointed toward an important role of glial pathology in mood disorders (Rajkowska and Miguel-Hidalgo, 2007). Post-mortem studies found alterations in density and protein expression of astrocytes (Ongur et al., 1998), a decrease in the number of glial cells in certain brain regions (Cotter et al., 2001), and an enlargement of glial cell bodies (Rajkowska et al., 1999) in brains of individuals suffering from a mood disorder. A comparison of post-mortem brain-tissue of younger and older patients suffering from MDD showed that, in older subjects, a reduction in pyramidal neurons could be found whereas in younger subjects only subtle neuronal damage but a prominent astroglial pathology could be found (Rajkowska and Miguel-Hidalgo, 2007). This raises the question if in major depression there is a primary dysfunction in glial cells which then leads to alterations in neuronal cells. A clinical study found increased levels of the glial marker S100 B in depressed patients which decreased slightly after treatment whereas the marker for neuronal damage, neuron specific enolase, did not differ in patients and healthy controls, emphasizing the important role of glial cells in mood disorders (Schroeter et al., 2010). A recent study found a possible role for human astroglial cells as stem cells as they developed a neuronal phenotype after incubation with imipramine (Cabras et al., 2010). Astrocytes therefore have multiple functions: they modulate neuroplasticity through secretion of neurotrophic factors like brain-derived neurotrophic factor (BDNF), remove excess glutamate from the synaptic cleft to protect neurons from its neurotoxic effects (Lobsiger and Cleveland, 2007) and play a role in neurotransmitter trafficking. These and other findings lead to the model of the so called tripartite glutamatergic synapse consisting of the pre- and postsynaptic neurons and a surrounding astrocyte (Araque et al., 1999). Most interestingly, ketamine, an NMDA antagonist, was recently found to display antidepressant properties with a rapid onset of action (Maeng and Zarate, 2007). Whether 
astroglia play a role in the antidepressant potency of ketamine is not clear, but it has been described that the acute administration of ketamine increases BDNF protein levels in the mouse brain. This study was focused on hippocampal neurons but similar mechanisms might take place in astroglial cells (Autry et al., 2011).

To eventually improve the therapy of MDD it thus justified to accrue deeper knowledge about the role of astrocytes in this disorder, with emphasis on their role in the mechanisms of antidepressant treatment. Here we investigated whether genes suggested to play an important role in the pathophysiology of affective disorders are differentially expressed in cultured astrocytes incubated with antidepressant agents. Brain-derived neurotrophic factor $(B d n f)$, the serotonin transporter $(5 \mathrm{Htt})$, and the dopamine transporter (Dat) genes were examined due to the large body of evidence suggesting an important role for those molecules in affective disorders (Levinson, 2006; Brunoni et al., 2008). Most importantly, their gene products, the dopamine, and the serotonin transporter, are the primary targets of antidepressant agents (Nieuwstraten and Dolovich, 2001; White et al., 2005; Watanabe et al., 2011). BDNF is thought to mediate the long-term effects of antidepressants by influencing neuronal plasticity and is central to the neurotrophin hypothesis of depression (Vaidya and Duman, 2001; Castren and Rantamaki, 2010). Furthermore, as we showed in previous studies that Nos3 knock-out mice display decreased adult neurogenesis and reduced responsiveness in a learned helplessness paradigm (Reif et al., 2004), and as we demonstrated an association of a polymorphism in the NOS3 gene with bipolar disorder (Reif et al., 2006), we speculated that the expression of NOS3 might also play a role in the mode of action of psychiatric medication and might be differentially regulated after incubation with antidepressants as well. Imipramine and escitalopram were chosen as antidepressants to contrast the broader (yet more noradrenergic) mode of action of the tricyclic compound imipramine to the highly selective serotonin reuptake inhibitor (SSRI) escitalopram.

\section{MATERIALS AND METHODS ASTROCYTE CELL CULTURE}

Primary astrocytes were isolated and cultured according to a method previously described with minor modifications (Deumens et al., 2004). In short, neonatal (postnatal day 1) Lewis rat pups were decapitated and the neocortex was dissected and cleared of meninges. The tissue was diced in small fragments and subsequently dissociated by passage through a nylon screen (100 $\mu \mathrm{m}$ mesh size). The suspension was centrifuged for $10 \mathrm{~min}$ at $1200 \mathrm{rpm}$, the supernatant discarded, and the pellet resuspended in $1 \mathrm{ml}$ culture medium (Dulbecco's Modified Eagles Medium containing glutamax-I, supplemented with $10 \%$ fetal calf serum, $100 \mathrm{U} / \mathrm{ml}$ penicillin, and $100 \mu \mathrm{g} / \mathrm{ml}$ streptomycin). Cells were plated into $25 \mathrm{~cm}^{2}$ cell culture flasks at a density of $10^{6}$ living cells per flask and incubated at $37^{\circ} \mathrm{C}$ and $5 \% \mathrm{CO}_{2}$. Culture medium was refreshed after 4-5 days and every 2 days thereafter. Confluence was reached after 10-12 days, after which contaminating cells (predominantly neurons and microglia) were removed by shaking the culture flasks at $135 \mathrm{rpm}$ on a gyratory shaker for 2 days. Purity of cultures was checked and proved that $>95 \%$ of cells were GFAP immunopositive astrocytes. After purification, cells were subcultured (ratio 1:2) in $25 \mathrm{~cm}^{2}$ cell culture flasks. Medium was refreshed every 2-3 days. Cultures were passed twice to obtain sufficient amount of cells. Stock solutions of $5 \mathrm{mM}$ of escitalopram hydrochloride (Lundbeck A/S, Valby, Denmark) and imipramine (Sigma-Aldrich Chemie, Zwijndrecht, The Netherlands) were freshly prepared in sterile $\mathrm{H}_{2} \mathrm{O}$ and protected from light. Medium was refreshed a few hours before addition of antidepressants. Final concentrations were 50 or $100 \mu \mathrm{M}$.

The concentrations of 50 and $100 \mu \mathrm{M}$ were chosen based on plasma levels during antidepressant treatment, and on the fact that antidepressants are concentrated (up to 10-fold) in the brain. Furthermore we kept in mind that concentrations of pharmacological agents used in cell culture experiments generally have to be higher as those encountered in in vivo situations due to the nature of cell culture conditions. Sterile $\mathrm{H}_{2} \mathrm{O}$ served as corresponding control. The incubation lasted $4 \mathrm{~h}$ to examine the acute effects of the antidepressant treatment.

To examine effects of chronic treatment, an incubation period of $24 \mathrm{~h}$ incubation was also investigated but there were no significant differences in RNA expression as compared to the control condition (data not shown). The complete experiment consisted of three different batches of primary astrocytes, where every culture condition was performed in triplicate. RNA was extracted from each cell culture sample and two sets of cDNA were transcribed from each RNA, resulting in six sets of cDNA were transcribed from each triplicate.

\section{ASSESSMENTS OF Bdnf, 5Htt, Dat, AND Nos3 RNA EXPRESSION AND STATISTICAL ANALYSIS}

After exposure to antidepressants, cells were washed twice with PBS Buffer and lysed in $175 \mu$ l of Buffer RLN provided by the RNeasy Mini Kit (Qiagen, Hilden, Germany) that was used to subsequently isolate total RNA. The RNA was reversed transcribed using the iScript ${ }^{\mathrm{TM}} \mathrm{cDNA}$ Synthesis Kit (Biorad, Hercules, USA). Real Time PCR was performed using the iCycler $\mathrm{iQ}^{\mathrm{TM}}$ Optical Module (Biorad, Hercules, USA). The optimization of the Real Time PCR reaction was performed according to the manufacturer's instructions but scaled down to $25 \mu$ l per reaction. Standard PCR conditions were used ( $\mathrm{iQ}^{\mathrm{TM}} \mathrm{SYBR}^{\circledR}$ Green Supermix protocol) and all reagents were provided in the iQ SYBR Green Supermix, including iTaq DNA polymerase (Biorad, Hercules, USA). Ribosomal $18 \mathrm{~S}$, Gapdh, and Arp were used to normalize each template using the normalization software GeNorm (Vandesompele et al., 2002). Standard curves for each amplification product were generated from 10-fold dilutions of pooled cDNA amplicons isolated from gel electrophoresis. For primer sequences, see Table 1 (MWG Biotech AG, Ebersberg, Germany).

\section{RESULTS}

We detected significant levels of Bdnf and 5Htt RNA expression in astrocytes under standard cell culture conditions, but were unable to measure Dat or Nos3 expression in any of the examined cell culture samples. Consistent with our hypothesis that antidepressant agents display a stimulatory effect on BDNF, quantitative PCR analysis demonstrated that the relative levels of $B d n f$ RNA expression in astrocytes were significantly increased when treated 
Table 1 | Primer sequences for quantitative PCR analysis.

\begin{tabular}{lll}
\hline Gene & Sense primer & Antisense primer \\
\hline Bdnf & $5^{\prime}$-TGC CGC AAA CAT GTC & $5^{\prime}$-GCT GTG ACC CAC TCG CTA \\
& TAT GAG G-3' & ATA C-3' \\
5Htt & $5^{\prime}$-GAC AGC CAC CTT CCC & 3'-CTA GCA AAC GCC AGG AGA $^{\prime}$ AC-5' \\
& TTA CA-3' & AC-5' \\
Nos3 & $5^{\prime}$-CCT TCC GCT ACC AGC & $5^{\prime}$-CAG AGA TCT TCA CTG CAT \\
& CAG A-3' & TGG CTA-3' \\
Gapdh & $5^{\prime}$-AAC GAC CCC TTC ATT & $5^{\prime}$-TCC ACG ACA TAC TCA GCA \\
& GAC-3' & C-3' \\
Arp & $5^{\prime}$-CGA CCT GGA AGT & $5^{\prime}$-ATC TGC TGC ATC TGC TTG-3' \\
& CCA ACT AC-3' & \\
18S & $5^{\prime}$-GAA ACT GCG AAT & $5^{\prime}$-CCA CAG TTA TCC AAG TAG \\
& GGC TCA TTA AA-3' & GAG AGG A-3'
\end{tabular}

The results of six sets of CDNA were pooled together, tested for normal distribution with the Shapiro-Wilk-and the Kolmogorov-Smirnow-test and then analyzed for statistical significance with non-parametric Kruskal-Wallis-test using SPSS software version V19 (IBM ${ }^{\circledast}$ SPSS $^{\circledast}$ Statistics V19, 2010, Armonk, USA).

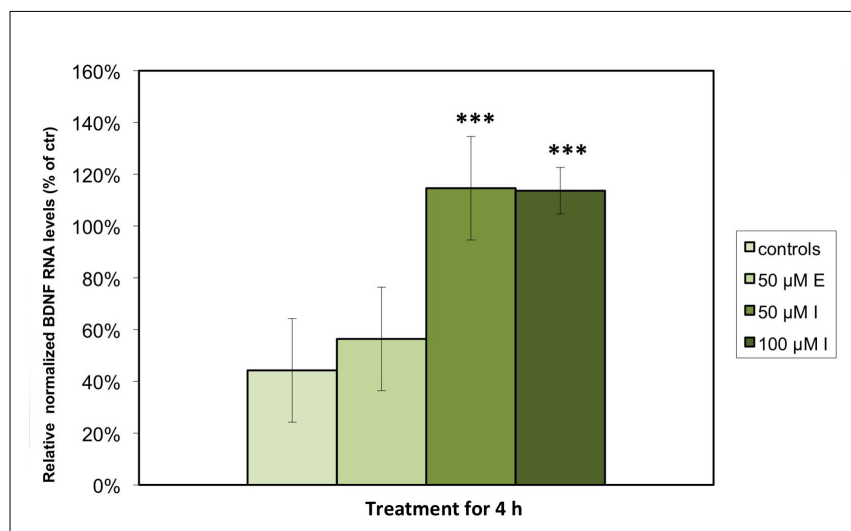

FIGURE 1 | Imipramine but not escitalopram increases the expression of Bdnf RNA in rat astrocyte cell cultures. The cells were incubated for $4 \mathrm{~h}$ with either $50 \mu \mathrm{M}$ escitalopram (E), $50 \mu \mathrm{M}$ imipramine (I), or $100 \mu \mathrm{M}$ imipramine (I). RNA levels of Bdnf were analyzed by quantitative real time PCR. Results are expressed as relative levels after normalization against housekeeping genes (Gapdh, Arp, and 18S) in percentages of control cells and represent the means of six independent experiments $\pm S D$. Data were statistically analyzed using non-parametric Kruskal-Wallis-Test. *** $p<0.001$

with either $50(p<0.001)$ or $100 \mu \mathrm{M}(p<0.001)$ imipramine as compared to control cells treated with vehicle. The escitalopramtreated astrocytes showed a nominal, but non-significant increase in $B d n f$ RNA expression (Figure 1). Expressed as \% of controls, the RNA level of $B d n f$ was significantly increased in the astrocytes incubated with 50 or $100 \mu \mathrm{M}$ imipramine $(100.4 \pm 12.0$ and $113.7 \pm 4.4 \%$ of controls), while only a nominal but nonsignificant increase was observed in cells treated with $50 \mu \mathrm{M}$ escitalopram after $4 \mathrm{~h}(57.6 \pm 8.0 \%$ of controls $)$. The cultured cells were also treated with $50 \mu \mathrm{M}$ of both substances for $24 \mathrm{~h}$; here, no significant changes in RNA expression were observed (data not shown). Tests to examine the BDNF protein levels are a subject to further studies.

As the primary molecular target of tricyclic antidepressants and SSRIs is (besides others) the serotonin transporter, we speculated that the RNA expression of $5 \mathrm{Htt}$ would be differentially regulated in cultured, treated astrocytes. While we detected stable expression of $5 \mathrm{Htt}$ RNA in astrocyte cell cultures, there was no significant change of its expression upon incubation with either antidepressant (not shown).

\section{DISCUSSION}

In the present study we demonstrated that treatment of primary astroglial cell culture isolated from new born rats with the antidepressant imipramine leads to an acute increase of $B d n f$ RNA expression. These data are in line with experiments on human tissue showing evidence for glial pathology, both in the pathogenesis of mood disorders as well as in the therapeutic effects of antidepressants (Hisaoka et al., 2011; Kim et al., 2011). In postmortem brain-tissue from human patients having suffered from major depression not only alterations in number and morphology in neuronal cells can be found, but also even more prominent changes in glial cells, especially astrocytes. The latter seem to be altered in size and number in MDD patients (Hercher et al., 2009; Altshuler et al., 2010). However, whether glial pathology is a major cause of mood disorders or rather a consequence of neuronal alterations is not clear at present. Astrocytes have been shown to not only provide metabolic and trophic support for neurons but also to modulate levels of neurotransmitters and to synthesize and release neurotrophic factors such as BDNF, glial cell-line derived neurotrophic factor (GDNF) and fibroblast growth factor 2 (FGF-2), and thus play an important role in adult neurogenesis (Hisaoka et al., 2007, 2011; Rajkowska and Miguel-Hidalgo, 2007). Not only do astrocytes synthesize neurotrophic factors, they also express neurotransmitter receptors and monoamine transporter proteins, at least in vitro (Duffy and MacVicar, 1995; Kang et al., 1998; Shelton and McCarthy, 2000) which led us to examine the expression of the respective genes upon antidepressant treatment. Accordingly, we here detected an expression of the monoamine transporter $5 \mathrm{Htt}$ as well as the neurotrophic factor $B d n f$. Our key finding was stimulated expression of the latter upon treatment with imipramine. Deficiencies in neurotrophic factors and subsequent reduction in neuronal resilience in the hippocampus may be an important element in the pathophysiology of major depression (Nibuya et al., 1995; Calabrese et al., 2011; Reus et al., 2011; Wolkowitz et al., 2011). Recently it has been shown that imipramine treatment in a mouse model of traumatic brain injury improved cognitive functioning probably by increasing the survival of newly generated neurons in the hippocampus (Han et al., 2011). Importantly, the long-term survival of those newly generated neuronal cells critically depends on BDNF (Lee et al., 2002). It is well established that treatment with antidepressant medication increases levels of BDNF, which is clinically associated with the reduction of depressive symptoms and responsiveness to medication (Chen et al., 2001; Teixeira et al., 2010). In the current study we hypothesized that the increase of $B d n f$ RNA after treatment with antidepressant agents is partly due to astroglial cells. It is well known that antidepressant agents lead to acute molecular consequences, such as 
the increase of serotonin in the synaptic cleft, but the symptom reduction in the treated depressed patient takes up to 3 weeks. The molecular mechanisms underlying this delayed clinical effect of treatment are still largely unknown. One hypothesis suggests that stimulated serotonin and noradrenalin receptors activate intracellular signaling pathways including the cAMP-CREB-cascade which then regulates the expression of BDNF, thereby leading to a higher rate of survival of newly generated neurons in the hippocampus. Engagement of these adaptive processes may explain in part the latency of clinical effect after antidepressant administration (Nibuya et al., 1996; van Praag et al., 2002; Duman, 2004). Therefore, an acute increase of BDNF triggered from astrocytes might be the starting point of a cascade which then leads to neuroadaptive processes underlying therapeutic response.

Consistent with our hypothesis, we demonstrated that treatment with imipramine for $4 \mathrm{~h}$ significantly increased the levels of $B d n f$ RNA in astrocyte cell culture. After $24 \mathrm{~h}$ treatment we could however not detect any significant changes in the levels of $B d n f$ RNA compared to untreated cells (data not shown) suggesting that the expressional regulation of $B d n f$ is an acute effect, which initiates other adaptive processes. These findings provide evidence that not only chronic, but also acute antidepressant treatment elicits an increase in expression of $B d n f$ RNA or BDNF protein level. Our point to the hypothesis that an acute increase in BDNF is caused by astroglial cells and that this leads to the chronic effects of antidepressant treatment, e.g., the enhancement of adult neurogenesis.

As astrocytes are in close contact with cerebral vasculature to regulate the neuronal microenvironment, it has also been supposed that astroglia might regulate the blood flow of the brain via release of nitric oxide probably produced by NOS-III (Wiencken and Casagrande, 1999). It was shown that astrocytes synthesize NOS-II after brain injury (Murphy et al., 1993). The failure to detect any relevant amount of Nos3 RNA in astrocytes in the present study however is consistent with earlier findings from Gath et al. (1999), who were also unable to demonstrate any NOS staining in glial fibrillary acidic protein positive astroglial cells derived from PCC7-Mz1 embryonic carcinoma cells, which however is not at par with a study detecting NOS3 mRNA expression in human astrocytoma T67 cells (Colasanti et al., 1998; Hamby et al., 2008). However, it has to be taken into account that cancer cells show a differential expressional profile probably explaining these discrepant findings. In our study, we used untransformed primary astrocytes to preserve in vivo properties as much as possible. Taken together,

\section{REFERENCES}

Altshuler, L. L., Abulseoud, O. A., Foland-Ross, L., Bartzokis, G., Chang, S., Mintz, J., Hellemann, G, and Vinters, H. V. (2010). Amygdala astrocyte reduction in subjects with major depressive disorder but not bipolar disorder. Bipolar Disord. 12, 541-549.

Angst, J., Angst, F., Gerber-Werder, R., and Gamma, A. (2005). Suicide in 406 mood-disorder patients with and without long-term medication: a 40 to 44 years' follow-up. Arch. Suicide Res. 9, 279-300.
Araque, A., Parpura, V., Sanzgiri, R. P., and Haydon, P. G. (1999). Tripartite synapses: glia, the unacknowledged partner. Trends Neurosci. 22, 208-215.

Autry, A. E., Adachi, M., Nosyreva, E., Na, E. S., Los, M. F., Cheng, P. F., Kavalali, E. T., and Monteggia, L. M. (2011). NMDA receptor blockade at rest triggers rapid behavioural antidepressant responses. Nature 475, 91-95.

Bal, N., Figueras, G., Vilaro, M. T., Sunol, C., and Artigas, F. (1997). Antidepreßant drugs inhibit a glial

astrocytes do not seem to express NOS-III and the only relevant source of this protein in the brain most likely is endothelium.

Furthermore, we have investigated whether monoamine transporters are expressed in astrocytes and if so, if this is changed by antidepressant treatment. Some antidepressants also possess dopaminergic mechanisms of action, e.g., bupropion, and triple reuptake inhibitors (i.e., substances inhibiting serotonin, norepinephrine, and dopamine reuptake) are on the verge of entering the market, and hence we not only tested for $5 \mathrm{Htt}$, but also the Dat. While Karakaya and associates (Takeda et al., 2002; Karakaya et al., 2007) demonstrated Dat expression in astrocytes, several other studies stated that the dopamine transporter can be nearly exclusively found in neuronal cells (Torres et al., 2003; Dahlin et al., 2007) which is consistent with the present study where we could not detect any relevant Dat RNA expression. However, it has to be said that there are presumably several subtypes of astroglial cells differing in specific protein expression, localization, and function which could explain these discrepancies (Halassa et al., 2007). In contrast, it has been shown that astrocytes in culture can take up serotonin and this can be blocked by SSRIs like fluoxetine (Bal et al., 1997; Inazu et al., 2001). It has therefore been speculated that astrocytes participate in the mode of action of this class of antidepressant drugs. In line with this, we detected expression of $5 \mathrm{Htt}$ in astroglia however no significant changes in expression upon either escitalopram or imipramine treatment were found.

Taken together, our data support the hypothesis that at least some tricyclic antidepressants, such as imipramine, lead to upregulation of BDNF via astroglial cells. It can therefore be assumed that astrocytes play an important role in the mode of action of antidepressants and probably the pathophysiological mechanisms of mood disorders in general.

\section{ACKNOWLEDGMENTS}

We thank Lundbeck A/S (Valby, Denmark) for the kind gift of escitalopram hydrochloride. This study was supported by the DFG (Grant RE1632/1-1, /1-3, and/5 to Andreas Reif, KFO 125 to Andreas Reif and Klaus-Peter Lesch; SFB 581 to Klaus-Peter Lesch, SFB TRR 58 to Andreas Reif and Klaus-Peter Lesch; RTG 1256/2 to Andreas Reif and Klaus-Peter Lesch), BMBF (IZKF Würzburg, 01KS9603, to Klaus-Peter Lesch; IZKF N-27-N, to Andreas Reif), and the EC (NEWMOOD LSHM-CT-2003-503474, to Klaus-Peter Lesch and Harry Steinbusch). We are grateful to T. Töpner for excellent technical support.

5-hydroxytryptamine transporter in rat brain. Eur. J. Neurosci. 9, 1728-1738.

Bromet, E., Andrade, L. H., Hwang, I., Sampson, N. A., Alonso, J., de Girolamo, G., de Graaf, R., Demyttenaere, K., Hu, C., Iwata, N., Karam, A. N., Kaur, J., Kostyuchenko, S., Lépine, J. P., Levinson, D., Matschinger, H., Mora, M. E., Browne, M. O., PosadaVilla, J., Viana, M. C., Williams, D. R., and Kessler, R. C. (2011). Crossnational epidemiology of DSM-IV major depressive episode. BMCMed. 9, 90. doi:10.1186/1741-7015-9-90
Brunoni, A. R., Lopes, M., and Fregni, F. (2008). A systematic review and meta-analysis of clinical studies on major depression and BDNF levels: implications for the role of neuroplasticity in depression. Int. J. Neuropsychopharmacol. 11, 1169-1180.

Cabras, S., Saba, F., Reali, C., Scorciapino, M. L., Sirigu, A., Talani, G., Biggio, G., and Sogos, V. (2010). Antidepressant imipramine induces human astrocytes to differentiate into cells with neuronal phenotype. Int. J. Neuropsychopharmacol. 13, 603-615. 
Calabrese, F., Molteni, R., Gabriel, C., Mocaer, E., Racagni, G., and Riva, M. A. (2011). Modulation of neuroplastic molecules in selected brain regions after chronic administration of the novel antidepressant agomelatine. Psychopharmacology (Berl.) 215, 267-275.

Castren, E., and Rantamaki, T. (2010). The role of BDNF and its receptors in depression and antidepressant drug action: Reactivation of developmental plasticity. Dev. Neurobiol. 70, 289-297.

Chen, B., Dowlatshahi, D., MacQueen, G. M., Wang, J. F., and Young, L. T. (2001). Increased hippocampal BDNF immunoreactivity in subjects treated with antidepressant medication. Biol. Psychiatry 50, 260-265.

Colasanti, M., Persichini, T., Fabrizi, C., Cavalieri, E., Venturini, G., Ascenzi, P., Lauro, G. M., and Suzuki, H. (1998). Expression of a NOS-III-like protein in human astroglial cell culture. Biochem. Biophys. Res. Commun. 252, 552-555.

Cotter, D., Mackay, D., Landau, S., Kerwin, R., and Everall, I. (2001). Reduced glial cell density and neuronal size in the anterior cingulate cortex in major depressive disorder. Arch. Gen. Psychiatry 58, 545-553.

Dahlin, A., Xia, L., Kong, W., Hevner, R., and Wang, J. (2007). Expression and immunolocalization of the plasma membrane monoamine transporter in the brain. Neuroscience 146, 1193-1211.

Deumens, R., Koopmans, G. C., Den Bakker, C. G., Maquet, V., Blacher, S., Honig, W. M., Jérôme, R., Pirard, J. P., Steinbusch, H. W., and Joosten, E. A. (2004). Alignment of glial cells stimulates directional neurite growth of CNS neurons in vitro. Neuroscience 125, 591-604.

Duffy, S., and MacVicar, B. A. (1995). Adrenergic calcium signaling in astrocyte networks within the hippocampal slice. J. Neurosci. 15, 5535-5550.

Duman, R. S. (2004). Role of neurotrophic factors in the etiology and treatment of mood disorders. $\mathrm{Neu}$ romolecular Med. 5, 11-25.

Gath, I., Steppuhn, A., Maelicke, A., Reinhardt, S., and Forstermann, U. (1999). Analysis of NO synthase expression in neuronal, astroglial and fibroblast-like derivatives differentiating from PCC7-Mz1 embryonic carcinoma cells. Eur. J. Cell Biol. 78, 134-142.

Halassa, M. M., Fellin, T., Takano, H., Dong, J. H., and Haydon, P. G. (2007). Synaptic islands defined by the territory of a single astrocyte. $J$. Neurosci. 27, 6473-6477.

Hamby, M. E., Gragnolati, A. R., Hewett, S. J., and Hewett, J. A. (2008). TGF beta 1 and TNF alpha potentiate nitric oxide production in astrocyte cultures by recruiting distinct subpopulations of cells to express NOS-2. Neurochem. Int. 52, 962-971.

Han, X., Tong, J., Zhang, J., Farahvar, A., Wang, E., Yang, J., Samadani, U., Smith, D. H., and Huang, J. H. (2011). Imipramine treatment improves cognitive outcome associated with enhanced hippocampal neurogenesis after traumatic brain injury in mice. J. Neurotrauma 28, 995-1007.

Hercher, C., Turecki, G., and Mechawar, N. (2009). Through the looking glass: examining neuroanatomical evidence for cellular alterations in major depression. J. Psychiatr. Res. 43, 947-961.

Hisaoka, K., Takebayashi, M., Tsuchioka, M., Maeda, N., Nakata, Y., and Yamawaki, S. (2007). Antidepressants increase glial cell line-derived neurotrophic factor production through monoamineindependent activation of protein tyrosine kinase and extracellular signal-regulated kinase in glial cells. J. Pharmacol. Exp. Ther. 321, 148-157.

Hisaoka, K., Tsuchioka, M., Yano, R., Maeda, N., Kajitani, N., Morioka, N., Nakata, Y., and Takebayashi, M. (2011). Tricyclic antidepressant amitriptyline activates fibroblast growth factor receptor signaling in glial cells: involvement in glial cell line-derived neurotrophic factor production. J. Biol. Chem. 286, 21118-21128.

Inazu, M., Takeda, H., Ikoshi, H., Sugisawa, M., Uchida, Y., and Matsumiya, T. (2001). Pharmacological characterization and visualization of the glial serotonin transporter. Neurochem. Int. 39, 39-49.

Kang, J., Jiang, L., Goldman, S. A., and Nedergaard, M. (1998). Astrocytemediated potentiation of inhibitory synaptic transmission. Nat. Neurosci. 1, 683-692.

Karakaya, S., Kipp, M., and Beyer, C. (2007). Oestrogen regulates the expression and function of dopamine transporters in astrocytes of the nigrostriatal system. J. Neuroendocrinol. 19, 682-690.

Kim, Y., Kim, S. H., Kim, Y. S., Lee, Y. H., Ha, K., and Shin, S. Y. (2011). Imipramine activates glial cell linederived neurotrophic factor via early growth response gene 1 in astrocytes. Prog. Neuropsychopharmacol. Biol. Psychiatry 35, 1026-1032.

Kupfer, D. J. (1991). Long-term treatment of depression. J. Clin. Psychiatry 52 (Suppl.), 28-34.

Lee, J., Duan, W., and Mattson, M. P. (2002). Evidence that brain-derived neurotrophic factor is required for basal neurogenesis and mediates, in part, the enhancement of neurogenesis by dietary restriction in the hippocampus of adult mice. J. Neurochem. 82, 1367-1375.

Levinson, D. F. (2006). The genetics of depression: a review. Biol. Psychiatry 60, 84-92.

Lobsiger, C. S., and Cleveland, D. W. (2007). Glial cells as intrinsic components of non-cell-autonomous neurodegenerative disease. Nat. Neurosci. 10, 1355-1360.

Maeng, S., and Zarate, C. A. Jr. (2007). The role of glutamate in mood disorders: results from the ketamine in major depression study and the presumed cellular mechanism underlying its antidepressant effects. Curr. Psychiatry Rep. 9, 467-474.

Manji, H. K., Moore, G. J., Rajkowska, G., and Chen, G. (2000). Neuroplasticity and cellular resilience in mood disorders. Mol. Psychiatry 5, 578-593.

Murphy, S., Simmons, M. L., Agullo, L., Garcia, A., Feinstein, D. L., Galea, E., Reis, D. J., Minc-Golomb, D., and Schwartz, J. P. (1993). Synthesis of nitric oxide in CNS glial cells. Trends Neurosci. 16, 323-328.

Nibuya, M., Morinobu, S., and Duman, R. S. (1995). Regulation of BDNF and trkB mRNA in rat brain by chronic electroconvulsive seizure and antidepressant drug treatments. J. Neurosci. 15, 7539-7547.

Nibuya, M., Nestler, E. J., and Duman, R. S. (1996). Chronic antidepressant administration increases the expression of cAMP response element binding protein (CREB) in rat hippocampus. J. Neurosci. 16, 2365-2372.

Nieuwstraten, C. E., and Dolovich, L. R. (2001). Bupropion versus selective serotonin-reuptake inhibitors for treatment of depression. Ann. Pharmacother. 35, 1608-1613.

Ongur, D., Drevets, W. C., and Price, J. L. (1998). Glial reduction in the subgenual prefrontal cortex in mood disorders. Proc. Natl. Acad. Sci. U.S.A. 95, 13290-13295.

Pittenger, C., and Duman, R. S. (2008). Stress, depression, and neuroplasticity: a convergence of mechanisms. Neuropsychopharmacology 33, 88-109.
Rajkowska, G., and Miguel-Hidalgo, J. J. (2007). Gliogenesis and glial pathology in depression. CNS Neurol. Disord. Drug Targets 6, 219-233.

Rajkowska, G., Miguel-Hidalgo, J. J., Wei, J., Dilley, G., Pittman, S. D., Meltzer, H. Y., Overholser, J. C., Roth, B. L., and Stockmeier, C. A. (1999). Morphometric evidence for neuronal and glial prefrontal cell pathology in major depression. Biol. Psychiatry 45, 1085-1098.

Reif, A., Schmitt, A., Fritzen, S., Chourbaji, S., Bartsch, C., Urani, A., Wycislo, M., Mössner, R., Sommer, C., Gass, P., and Lesch, K. P. (2004). Differential effect of endothelial nitric oxide synthase (NOS-III) on the regulation of adult neurogenesis and behaviour. Eur. J. Neurosci. 20, 885-895.

Reif, A., Strobel, A., Jacob, C. P., Herterich, S., Freitag, C. M., Topner, T., Mössner, R., Fritzen, S., Schmitt, A., and Lesch, K. P. (2006). A NOS-III haplotype that includes functional polymorphisms is associated with bipolar disorder. Int. J. Neuropsychopharmacol. 9, 13-20.

Reus, G. Z., Stringari, R. B., Ribeiro, K. F., Ferraro, A. K., Vitto, M. F., Cesconetto, P., Souza, C. T., and Quevedo, J. (2011). Ketamine plus imipramine treatment induces antidepressant-like behavior and increases CREB and BDNF protein levels and PKA and PKC phosphorylation in rat brain. Behav. Brain Res. 221, 166-171.

Schroeter, M. L., Abdul-Khaliq, H., Sacher, J., Steiner, J., Blasig, I. E., and Mueller, K. (2010). Mood disorders are glial disorders: evidence from in vivo studies. Cardiovasc. Psychiatry Neurol. 2010, 780645

Shelton, M. K., and McCarthy, K. D. (2000). Hippocampal astrocytes exhibit Ca2+-elevating muscarinic cholinergic and histaminergic receptors in situ. J. Neurochem. 74, 555-563.

Sullivan, P. F., Neale, M. C., and Kendler, K. S. (2000). Genetic epidemiology of major depression: review and meta-analysis. Am. J. Psychiatry 157, 1552-1562.

Takeda, H., Inazu, M., and Matsumiya, T. (2002). Astroglial dopamine transport is mediated by norepinephrine transporter. Naunyn Schmiedebergs Arch. Pharmacol. 366, 620-623.

Teixeira, A. L., Barbosa, I. G., Diniz, B. S., and Kummer, A. (2010). Circulating levels of brain-derived neurotrophic factor: correlation with mood, cognition and motor function. Biomark. Med. 4, 871-887. 
Torres, G. E., Gainetdinov, R. R., and Caron, M. G. (2003). Plasma membrane monoamine transporters: structure, regulation and function. Nat. Rev. Neurosci. 4, 13-25.

Vaidya, V. A., and Duman, R. S. (2001). Depresssion - emerging insights from neurobiology. Br. Med. Bull. 57, 61-79.

Vandesompele, J., De Preter, K., Pattyn, F., Poppe, B., Van Roy, N., De Paepe, A., and Speleman, F. (2002). Accurate normalization of real-time quantitative RT-PCR data by geometric averaging of multiple internal control genes. Genome Biol. 3, RESEARCH0034.

van Praag, H., Schinder, A. F., Christie, B. R., Toni, N., Palmer, T. D., and Gage, F. H. (2002).
Functional neurogenesis in the adult hippocampus. Nature 415, 1030-1034.

Watanabe, N., Omori, I. M., Nakagawa, A., Cipriani, A., Barbui, C., Churchill, R., and Furukawa, T. A. (2011). Mirtazapine versus other antidepressive agents for depression. Cochrane Database Syst. Rev. 12, CD006528.

White, K. J., Walline, C. C., and Barker, E. L. (2005). Serotonin transporters: implications for antidepressant drug development. AAPS J. 7, E421-E433.

Wiencken, A. E., and Casagrande, V. A. (1999). Endothelial nitric oxide synthetase (eNOS) in astrocytes: another source of nitric oxide in neocortex. Glia 26, 280-290.
Wolkowitz, O. M., Wolf, J., Shelly, W., Rosser, R., Burke, H. M., Lerner, G. K., Reus, V. I., Nelson, J. C., Epel, E. S., and Mellon, S. H. (2011). Serum BDNF levels before treatment predict SSRI response in depression. Prog. Neuropsychopharmacol. Biol. Psychiatry 35, 1623-1630.

Conflict of Interest Statement: The authors declare that the research was conducted in the absence of any commercial or financial relationships that could be construed as a potential conflict of interest.

Received: 24 October 2011; accepted: 26 March 2012; published online: 20 April 2012.
Citation: Kittel-Schneider S, Kenis G, Schek J, van den Hove D, Prickaerts Lesch K-P, Steinbusch $H$ and Reif A (2012) Expression of monoamine transporters, nitric oxide synthase 3, and neurotrophin genes in antidepressantstimulated astrocytes. Front. Psychiatry 3:33. doi: 10.3389/fpsyt.2012.00033

This article was submitted to Frontiers in Molecular Psychiatry, a specialty of Frontiers in Psychiatry.

Copyright (c) 2012 Kittel-Schneider, Kenis, Schek, van den Hove, Prickaerts, Lesch, Steinbusch and Reif. This is an open-access article distributed under the terms of the Creative Commons Attribution Non Commercial License, which permits non-commercial use, distribution, and reproduction in other forums, provided the original authors and source are credited. 